University of Wollongong

Research Online

Australian Institute for Innovative Materials -

Papers

Australian Institute for Innovative Materials

$1-1-2020$

\title{
Preparation and Characterisation of Metallorganic Precursors Derived Iron Oxides on Porous Silicon Layers
}

Sivakumar Balakrishnan

Yurii K. Gun'ko

Gerhard F. Swiegers

University of Wollongong, swiegers@uow.edu.au

Tatiana S. Perova

Follow this and additional works at: https://ro.uow.edu.au/aiimpapers

Part of the Engineering Commons, and the Physical Sciences and Mathematics Commons

Research Online is the open access institutional repository for the University of Wollongong. For further information contact the UOW Library: research-pubs@uow.edu.au 


\title{
Preparation and Characterisation of Metallorganic Precursors Derived Iron Oxides on Porous Silicon Layers
}

\author{
Abstract \\ Porous silicon has generated interest in scientific community after its photoluminescence discovery and \\ thereafter, research was focused on to the chemical functionalization of silicon and subsequent \\ anchoring of nanoparticles onto silicon surface. In the present work, the porous silicon has been \\ effectively modified with magnetic nanoparticles which were prepared through metallorganic approach. \\ The as-fabricated magnetic-porous silicon composites were characterised using FTIR and Raman \\ spectroscopies, Scanning Electron Microscopy (SEM) as well as magnetic measurements.

\section{Keywords} \\ preparation, characterisation, iron, metallorganic, precursors, derived, layers, silicon, porous, oxides \\ Disciplines \\ Engineering | Physical Sciences and Mathematics

\section{Publication Details} \\ Balakrishnan, S., Gun¿Ko, Y. K., Swiegers, G. F. \& Perova, T. S. (2020). Preparation and Characterisation of \\ Metallorganic Precursors Derived Iron Oxides on Porous Silicon Layers. Materials Science Forum, 995 \\ 63-68.
}




\title{
Preparation and Characterisation of Metallorganic Precursors Derived Iron Oxides on Porous Silicon Layers
}

\author{
Sivakumar Balakrishnan ${ }^{1,2, a}$, Yurii K. Gun'ko ${ }^{1, b}$, Gerhard F. Swiegers ${ }^{3, c}$ \\ and Tatiana S. Perova ${ }^{4, d}$ \\ ${ }^{1}$ School of Chemistry, Trinity College Dublin, The University of Dublin, Dublin 2, Ireland \\ ${ }^{2}$ Department of Applied Sciences, PNG University of Technology (Unitech), Papua New Guinea \\ ${ }^{3}$ Intelligent Polymer Research Institute, University of Wollongong, NSW 2522, Australia \\ ${ }^{4}$ School of Engineering, Trinity College Dublin, The University of Dublin, Dublin 2, Ireland \\ asivakumar.balakrishnan@pnguot.ac.pg, bigounko@tcd.ie, cswiegers@uow.edu.au, \\ dperovat@tcd.ie
}

Keywords: Porous silicon, magnetic nanoparticles, FTIR, Raman spectroscopy

\begin{abstract}
Porous silicon has generated interest in scientific community after its photoluminescence discovery and thereafter, research was focused on to the chemical functionalization of silicon and subsequent anchoring of nanoparticles onto silicon surface. In the present work, the porous silicon has been effectively modified with magnetic nanoparticles which were prepared through metallorganic approach. The as-fabricated magnetic-porous silicon composites were characterised using FTIR and Raman spectroscopies, Scanning Electron Microscopy (SEM) as well as magnetic measurements.
\end{abstract}

\section{Introduction}

The ability of porous silicon to incorporate various types of nanoparticles such as magnetic and semiconducting (quantum dots) nanoparticles is an interesting aspect in porous silicon chemistry. This is feasible because of its large surface area, which can be easily functionalised using chemical methods. Incorporation of nanoparticles and other organic materials onto porous silicon has been followed using various optical and electron microscopies. For example, Martin et al [1] reported on the incorporation of naphthalimide derivates onto nanostructured silicon and studied their optical responses using photoluminescence (PL) spectroscopy. Their studies showed that anchoring of naphalimide layers have happened mainly through hydrogen bridges of PS and results of which were followed with a shift in PL spectra. On the other hand, Gokarna et al reported on the metal sulphide particles onto porous silicon and studied the as-formed ultra-thin films of metal sulphides using PL spectroscopy and Hall measurements [2].

Magnetic nanoparticles are known for its applications in various fields [3] and the material has been studied extensively over the past few decades. The unique properties of the nanoparticles combined with those of the silicon or porous silicon might results in new composite materials with various applications [4]. The surface of porous silicon modified using amorphous iron oxide nanoparticles has proved to possess very interesting properties [5]. The incorporation of $\mathrm{Fe}_{2} \mathrm{O}_{3}$ nanoparticles onto flat silicon wafer and further heat treatment leading to multiple functionality (magnetic, metallic, semiconducting, insulating and optical) has been reported in literature, in which the authors describe about a "plug and play" approach where externally synthesized nanoparticles of desired size and functions are incorporated onto the semiconductor surface [6].

There are various methods by which nanoparticles can be deposited onto porous silicon and among them are electroless metal deposition, metal salt dissolution etc [7]. Researchers have used functionalised magnetic materials as a method to anchor magnetic nanoparticles on to silicon. For example, Altavilla et al., reported on the immobilisation of trimethoxy-7-octen-1-yl silane functionalised magnetite nanoparticles onto a hydrogen-terminated silicon surface [8]. In another report, authors describe a method to produce $2 \mathrm{D}$ arrays of magnetic nanoparticles on silicon after 
the semiconducting substrate was prepatterned with an array of hydrophilic grids separated by hydrophobic self-assembled monolayers (SAMs). Further, these arrays were treated with precursors of magnetite nanoparticles [9].

Most of the reported articles on iron based magnetic nanoparticles on to silicon (and porous silicon) were prepared either through the direct incorporation of magnetic nanoparticles on to silicon substrates or through the preparation of magnetic nanoparticles from metal salts in alkaline solution and then its subsequent incorporation onto silicon [5, 10]. However, in this paper, we report on the metallorganic approach, where the magnetic nanoparticles that are prepared through a metallorganic route and are anchored onto the porous silicon substrate after suitably functionalising the porous silicon matrix. To the best of our knowledge, this is a novel approach for the preparation of magnetic nanoparticle-porous silicon composite materials. The as-prepared materials were characterised using various characterisation methods such as FTIR, Raman and magnetic measurements.

\section{Experimental}

Samples preparation. All preparation and handling of starting materials and subsequent products were carried out under vacuum or argon by using Schlenk techniques. Solvents were dried over sodium-potassium alloy and distilled under argon prior to use and then condensed into a reaction flask under vacuum shortly before use. The starting materials Sodium t-Butoxide or $\left(\mathrm{CH}_{3}\right)_{3} \mathrm{CONa}$ (given as $\mathrm{NaOBu}^{\mathrm{t}}$ in this paper) and $\mathrm{FeBr}_{2}$ (ferrous bromide) were purchased from Aldrich.

Single crystal (100)-oriented, Czochralski-grown, p-type Si wafers of resistivity, $\rho=10 \Omega \cdot \mathrm{cm}$ have been used as a starting material for the present investigations. In this procedure of anodic etching, p-type $\operatorname{Si}(100) 3$ inch wafer was cut into $(1 \mathrm{~cm} \mathrm{x} 1 \mathrm{~cm})$ pieces and was treated with with $4 \%$ $\mathrm{HF}$ (Hydrofluoric acid) in DMF or $\left(\mathrm{CH}_{3}\right)_{2} \mathrm{NCO}$ (dimethyl formamide) in a Teflon cell. Prior to treating with $\mathrm{HF}$ in DMF, silicon wafers $(1 \mathrm{~cm} \times 1 \mathrm{~cm})$ were first etched by a $2 \% \mathrm{HF}$ for 10 minutes followed by rinsing with de-ionised water (Millipore, $18.2 \mathrm{M} \Omega . \mathrm{cm}$ ) taking less than one minute. These etching conditions removes the native oxide layer which has been formed on the silicon or porous silicon surface and results in the formation of a hydrogen terminated silicon surface [11]. The samples were then dried under the presence of argon gas or compressed air.

Preparation of iron oxide from metallorganic precursors. In the present study, we have used a metallorganic precursor and a sol-gel approach to prepare iron oxide-porous silicon composite materials. The iron oxides were prepared using new metallorganic iron(II) alkoxide precursor, $\left[\mathrm{Fe}(\mathrm{OBut})_{2}(\mathrm{THF})\right]_{2}$, which has been previously reported in [12], as single source precursor for the preparation of magnetite and maghemite nanoparticles. In brief, solution of $\mathrm{NaOBu}^{\mathrm{t}}(0.68 \mathrm{~g}$, $7.08 \mathrm{mmol})$ was added to $\mathrm{FeBr}_{2}(0.76 \mathrm{~g}, 3.54 \mathrm{mmol})$ in dry degassed THF $(100 \mathrm{ml})$ at about $0{ }^{\circ} \mathrm{C}$ under argon. The mixture was stirred for $24 \mathrm{~h}$ at ambient temperature, filtered and the filtrate then was used for further reactions. The porous silicon samples were hydroxyl functionalized, prior to the reactions, as reported earlier [13] with slight modifications. Briefly, for the hydroxyl functionalization the porous silicon samples were cleaned for 1 hour in a $\mathrm{H}_{2} \mathrm{SO}_{4} / \mathrm{H}_{2} \mathrm{O}_{2}(7: 3 \mathrm{v} / \mathrm{v})$ mixture at $\sim 80^{\circ} \mathrm{C}$ and then cooled to room temperature. The cleaned substrates were rinsed with de-ionised water and then treated further with a $\mathrm{H}_{2} \mathrm{O} / \mathrm{H}_{2} \mathrm{O}_{2} / \mathrm{NH}_{3}(5: 1: 1 \mathrm{v} / \mathrm{v} / \mathrm{v})$ mixture and dried under vacuum. The hydroxylated porous silicon samples were treated with $\left[\mathrm{Fe}\left(\mathrm{OBu}^{t}\right)_{2}(\mathrm{THF})\right]_{2}$ precursor solution in dry THF and subjected to sonication. After the ultrasonic treatment, the PS samples were washed with dry diethyl ether, twice with wet diethyl ether followed by drying under vacuum. Then porous silicon samples were heated up to $100^{\circ} \mathrm{C}$ under vacuum for 12 hours. SEM image of porous Si sample before and after deposition of iron oxide is shown in Figs. 1a and $1 \mathrm{~b}$.

FTIR spectroscopy. Fourier transform infrared (FTIR) measurements were performed in transmission mode using a Digilab FTS-6000 spectrometer. The sample was placed either in the main chamber of spectrometer, using a Perkin-Elmer micro-sampling attachment, or on the positional stage of a UMA 500 IR microscope. For measurements in the main chamber a wide band 
MCT detector in the wavenumber range of 450-6000 $\mathrm{cm}^{-1}$ with a resolution of $2 \mathrm{~cm}^{-1}$ and $8 \mathrm{~cm}^{-1}$ was used. A narrow band MCT detector with a spectral range of $4500-750 \mathrm{~cm}^{-1}$ was used in a UMA 500 IR microscope. A total of 128 scans were summed up to increase the signal-to-noise ratio in both cases.

Raman spectroscopy. Room temperature Raman spectra were measured with a Renishaw 1000 micro-Raman system. The excitation wavelength was $514.5 \mathrm{~nm}$ from an $\mathrm{Ar}^{+}$ion laser (Laser Physics Reliant 150 Select Multi-Line) with a typical laser power of $\sim 10 \mathrm{~mW}$. The 50x magnifying objective of the Leica microscope focused the laser beam into a spot of about $1 \mu \mathrm{m}$ in diameter.

Magnetic measurements. Magnetic measurements were carried out both at $5 \mathrm{~K}$ and $300 \mathrm{~K}$ using a MPMS super-conducting quantum interference device (SQUID) magnetometer.

\section{Results and Discussions}

The preparation of iron oxides from metallorganic precursor route gives two types of magnetic materials - magnetite $\left(\mathrm{Fe}_{3} \mathrm{O}_{4}\right)$ and maghemite $\left(\gamma-\mathrm{Fe}_{2} \mathrm{O}_{3}\right)$. The preparation of iron oxide layers on porous silicon samples were performed according to the scheme depicted in Fig. 2. Briefly, the hydroxylated porous silicon samples were treated with $\left[\mathrm{Fe}(\mathrm{OBut})_{2}(\mathrm{THF})\right]_{2}$ precursor solution in dry THF and subjected to sonication. After the ultrasonic treatment, the PS samples (composite samples) were washed with diethyl ether and heated up to $100^{\circ} \mathrm{C}$ under vacuum for 12 hours. The mechanism of formation of iron oxide involves an oxidation of $\mathrm{Fe}$ (II) into $\mathrm{Fe}$ (III) by ultrasonically generated radical and peroxide species from THF. A similar type of process has been reported in [14]. The formation of $\mathrm{Fe}_{2} \mathrm{O}_{3}$ nanoparticles proceeds via precursor materials containing $-\mathrm{Fe}-(\mathrm{OH})-$ $\mathrm{Fe}-[12]$ interacts with the - $\mathrm{OH}$ groups of porous silicon. Further, the nanoparticles get anchored on the surface of the silicon material. The thermal treatment at $100^{\circ} \mathrm{C}$ allows the completion of conversion from the precursor into iron oxide coating.
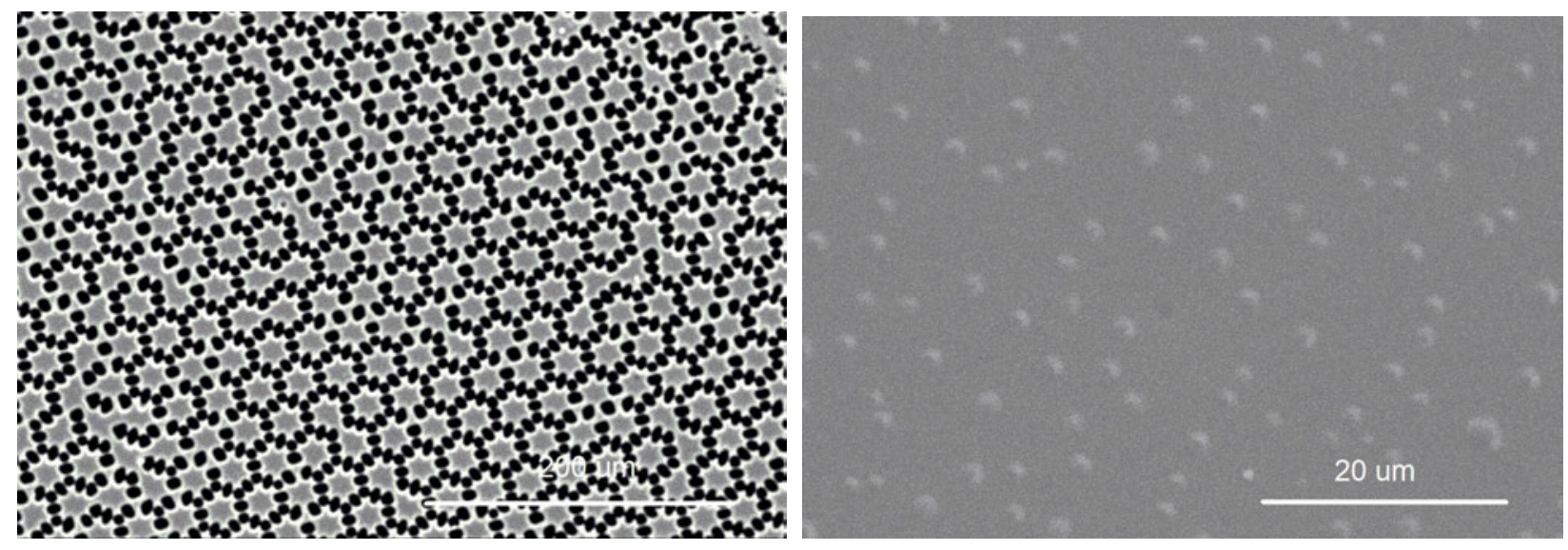

Figure 1. SEM images of p-type porous Si sample before (a) and after (b) deposition of iron oxide layer
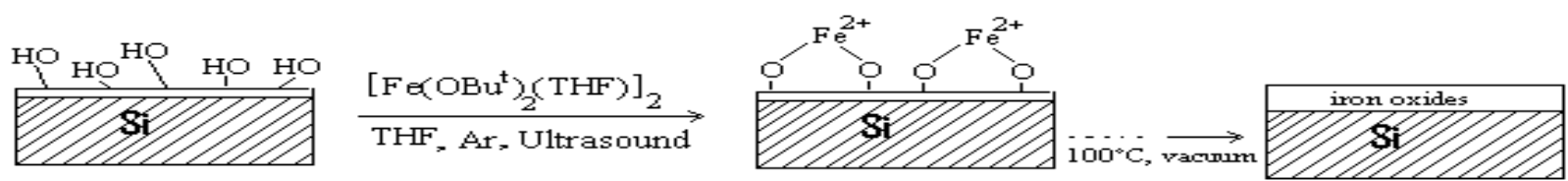

Figure 2. A schematic representation of the preparation of iron oxide layers on porous silicon surface 
The SEM image of the p-type porous silicon alone shows the pores in the range 5 to $10 \mu \mathrm{m}$ range and the figure 1 (b) shows the uniform deposition (thin layer) of iron oxide layer on the silicon surface with the occasional bigger particles that are formed on the surface of the substrate. The asprepared layers have been studied by FTIR and micro-Raman spectroscopy. Figure 3a shows the infrared (IR) spectrum of iron oxide layers on porous silicon and it provide information about the various stretching and bending modes of iron oxides on porous silicon. A band at $1625 \mathrm{~cm}^{-1}$ is characteristic for bending mode of $\mathrm{Fe}-\mathrm{OH}$ groups, which are present at the surface of iron oxides. The IR spectrum shows a shoulder at $1027 \mathrm{~cm}^{-1}$ which was assigned to $\mathrm{Fe}-\mathrm{O}-\mathrm{Si}$ stretching vibrations [15]. The broad bands at $1097 \mathrm{~cm}^{-1}$ and $825 \mathrm{~cm}^{-1}$ were attributed to Si-O and $\mathrm{Fe}-\mathrm{O}$ bonds respectively $[11,16]$. The presence of $\mathrm{Fe}-\mathrm{O}-\mathrm{Si}$ bands, $\mathrm{Si}-\mathrm{O}$ bands and $\mathrm{Fe}-\mathrm{O}$ bands confirm the bond formation between the substrate (porous silicon) and the magnetic nanoparticles formed from the metal alkoxide reaction route. Thus, the infrared spectroscopy provides clear information about the various bonds that are formed when magnetic nanoparticles interacted with the silicon substrate under the conditions outlined in the experimental section.

Raman spectrum of the sample (Fig. 3b) clearly shows peaks belonging to a mixture of magnetite and maghemite [17]. The peaks at 193 and around $680 \mathrm{~cm}^{-1}$ are attributed to magnetite, whereas the peaks at 161,617 and $710 \mathrm{~cm}^{-1}$ are attributed to maghemite [17]. The presence of maghemite peaks could also arise from the local heating of the sample by the excitation laser [18]. It has been reported that excitation laser of the Raman source can induce localised heating on the sample and thereby convert some of the magnetite forms to maghemite form [18]. The strong peak around $520 \mathrm{~cm}^{-1}$ is attributed to silicon substrate [19].
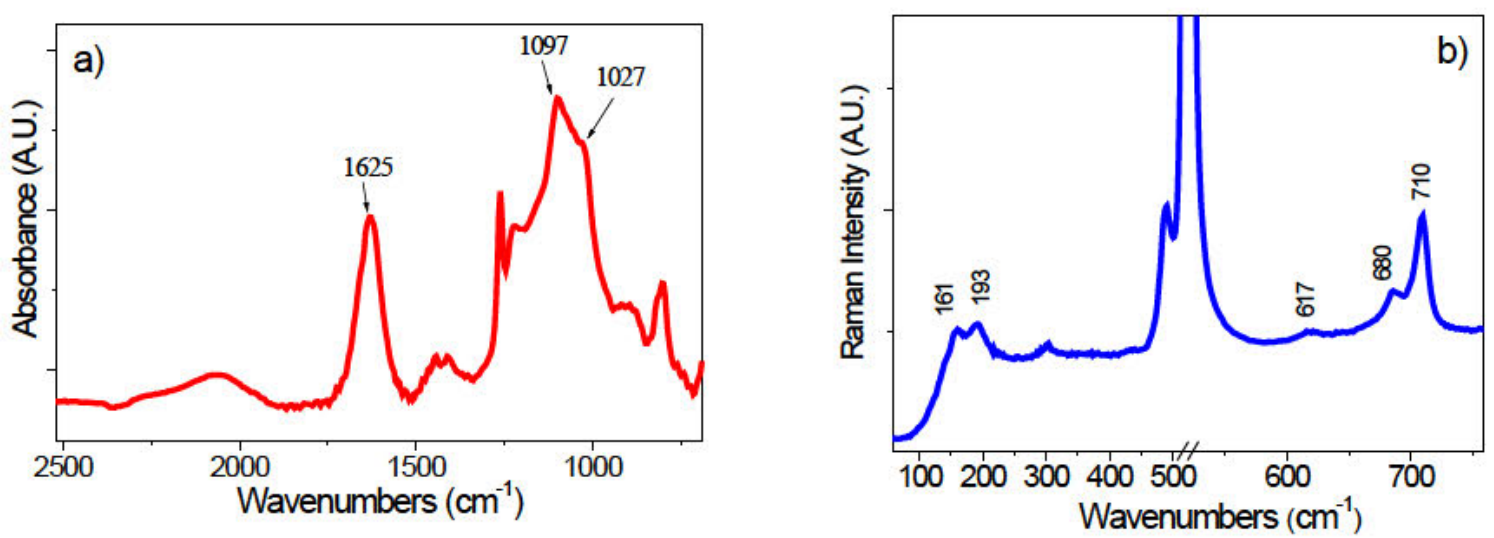

Figure 3. (a) FTIR spectrum of iron oxide layers on porous silicon. (b) Raman spectrum demonstrating the presence of magnetite and maghemite iron oxides on porous $\mathrm{Si}$

The magnetic measurement studies (magnetic moment) on the iron oxide-porous silicon composite sample (figure 4) showed a weak magnetic response of the iron oxide layer on porous silicon. This can be attributed to the presence of very thin layer of magnetic iron oxide. The magnetisation (which is measured in $\mathrm{emu} / \mathrm{g}$ or $\mathrm{Am}^{2} / \mathrm{kg}$ ) of the sample is limited in this study due to the formation of thin layer sample as such the amount of material (magnetic nanoparticles) on the surface could not be calculated. Therefore, the magnetic moments of the material could be determined and it gives information that the material formed, through this novel metallorganic approach, is magnetic in nature. 


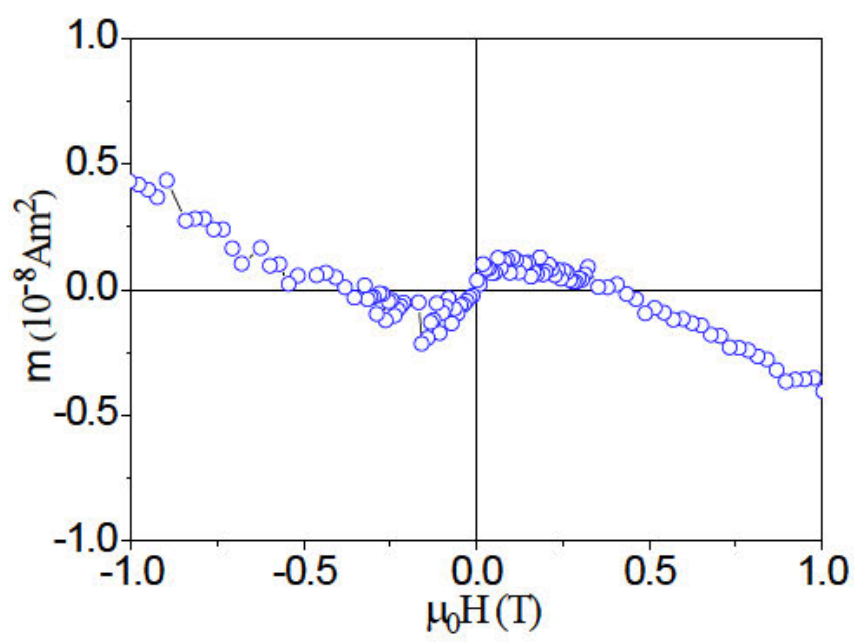

Figure 4. Magnetic measurements of the iron oxide-porous silicon composite

\section{Conclusions}

The present paper reported on the functionalization of porous silicon with iron oxides, which were prepared through metallorganic route. The samples (functionalized PS) from the present work are conveniently characterized by FTIR, Raman, SEM and magnetic measurements. The results published in this paper are first of its kind in which the porous silicon - magnetic iron oxides composites are formed. It is anticipated that these preliminary results will pave way for more metallorganic approaches on porous silicon.

\section{Acknowledgements}

We gratefully acknowledge Enterprise Ireland (Basic Research Grant Scheme) and HEA PRLTI programme for financial support and staff members of the Electron Microscopy Unit of TCD for their kind support during this work. The authors thank Dr Venkatesan for useful discussions and carrying out the magnetic measurements.

\section{References}

[1] E. Martín, V. Torres-Costa, R. J. Martín-Palma, C. Bousoño, J. Tutor-Sánchez and J. M. Martínez-Duart, Journ. Electr. chem. soc., Vol. 153, no.8 (2006) D134.

[2] A. Gokarna, S. V. Bhoraskar, N. R. Pavaskar and S. D. Sathaye, phys. stat. sol (a), Vol.182 (2000) 175.

[3] (a) A. G. Audram, and A. P. Huguenard, U.S. Patent 4,302,523 (1981). (b) R. F. Ziolo, U.S. Patent 4,474,866 (1984). (c) N. M. Pope, R. C. Alsop, Y.-A. Chang and A. K. Sonith: J. Biomed. Mater. Res., Vol. 28 (1994) p.449. (d) S. P. Bhatnagar and R. E. Rosensweig: J. Magn. Magn. Mater., Vol. 149 (1995) p.198.

[4] (a) K. S. Nustad, T. E. Funderud, A. Berge and J. Ugelstad, in Scientific Methods for the Study of Polymer Colloids and their Applications, ed. F. Candau and R. H. Ottewill, 1990, Kluwer Academic, Dordrecht, 517. (b) J. Ugelstad, P. Stenstad, L. Kilaas, W. S. Prestvik, P. Herje, A. Berge and E. Hornes: Blood Purification, Vol. 11 (1993) p.349.

[5] K. Prabhakaran, Y. Watanabe, K. G. Nath, Y. Homma, T. Ogino, K. V. P. M. Shafi and A. Ulman: Surf. Sci., Vol. 545 (2003) p.191.

[6] K. Prabhakaran, K. V. P. Mohammed Shafi, A. Ulman, and T. Ogino, Adv. Mater., Vol.13 (2001) p.1859.

[7] C. Xu, X. Zhang, K. N. Tu and Y. Xie, J. Electrochem. Soc., Vol. 154 (2007) p.D170. 
[8] C. Altavilla, E. Ciliberto, D. Gatteschi and C. Sangregorio, Adv. Mater. Vol. 17, no. 8, (2005), p.1084.

[9] Z. Zhong, B. Gates and Y. Xia, Langmuir, Vol.16 (2000) 10369.

[10] (a) S. Balakrishnan, Y. K. Gun'ko, T. S. Perova, R. A. Moore, M. Venkatesan, A. P. Douvalis and P. Bourke, Small, Vol. 2 (2006) 864. (b) S.G. Starodoubtseva, E.V. Saenkoa, A.R. Khokhlova, V.V. Volkovb and K.A. Dembob, Micro. Electr. Engg., 69 (2003) 324.

[11] J. E. Bateman, R. D. Eagling, B. R. Horrocks, A. Houlton and D. R. Worrall: Chem. Commun., Vol. 23 (1997) p.2275.

[12] G. B. Biddlecombe, Y. K. Gun'ko, J. M. Kelly, S. C. Pillai, J. M. D. Coey, M. Venkatesan and A. P. Douvalis: J. Mater. Chem., Vol.11 (2001) p.2937.

[13] R. Cohen, N. Zenou, D. Cahen, and S. Yitzchaik: Chem. Phys. Lett., Vol.279 (1997) p.270

[14] (a) X. Cao, Yu. Koltypin, G. Katabi, R. Prozorov, I. Felner and A. Gedanken: J. Mater. Chem., Vol.7 (1997) p.1007; (b) R. Vijayakumar, Yu. Koltypin, I. Felner and A. Gedanken: Mater. Sci. and Eng. A., Vol.286 (2000) p.101; (c) R. V. Kumar, Yu. Koltypin, Y. S. Cohen, Y. Cohen, D. Aurbach, O. Palchik, I. Felner and A. Gedanken: J. Mater. Chem., Vol.10 (2000) p.1125.

[15] A. W. Jung: Magnetic Resonance Imaging, Vol.13 (1995) p.675.

[16] E. Pinakoulaki, S. Gemeinhardt, M. Saraste, and C. Varotsis: J. Biol. Chem., Vol.277 (2002) p.23407.

[17] (a) D. Bersani, P. P. Lottici and A. Montenero: J. Raman Spectrosc., Vol.30 (1999) 355. (b) O. N. Shebanova and P. Lazor: J. Solid-State Chem., Vol.174 (2003) p.424.

[18] O. N. Shebanova and P. Lazor, J. Raman spec., 34 (2003) 845.

[19] V. Craciun, C. B. Leborgne, E. J. Nicholls and I. W. Boyd: Appl. Phys. Lett., Vol, 69 (1996) 1506. 